\title{
Primary Extranodal Non-Hodgkin's Lymphoma Mimicking a Painful Gingival Swelling: A Case Report
}

\author{
Ayhan Tetik ${ }^{*}$, Cem Peskersoy'2, Banu Özveri Koyuncu ${ }^{3}$, Murat Cihan Solmaz ${ }^{3}$, \\ Güray Saydam4 \\ ${ }^{1}$ Department of Oral and Maxillofacial Surgery, Izmir Training Dental Hospital, İzmir, Turkey \\ ${ }^{2}$ Department of Restorative Dentistry, Faculty of Dentistry, Ege University, Izmir, Turkey \\ ${ }^{3}$ Department of Oral and Maxillofacial Surgery, Faculty of Dentistry, Ege University, Izmir, Turkey \\ ${ }^{4}$ Department of Hemathology, Faculty of Medicine, Ege University, İzmir, Turkey \\ Email: *ayhantetikdt@hotmail.com
}

Received 11 January 2016; accepted 26 January 2016; published 29 January 2016

Copyright (C) 2016 by authors and OALib.

This work is licensed under the Creative Commons Attribution International License (CC BY).

http://creativecommons.org/licenses/by/4.0/

c. (i) Open Access

\section{Abstract}

Diffuse large B cell lymphoma (DLBCL), the most common subtype of non-Hodgkin's lymphoma (NHL), is an aggressive, rapidly growing neoplasm which is the most common lymphoid neoplasm affecting adults. Jaw involvement of NHL is rare, but among jaw lesions, the maxilla is more frequently involved than the mandible. Primary lymphoma of the mandible is often misdiagnosed clinically. A 43-year-old man admitted to the Ege University, Department of Oral and Maxillofacial Surgery at the Faculty of Dentistry with one month complaint of gingival pain and swelling in the left side of mandibular premolar area. Biopsy was planned and was done to send for histopathological examination. Histopathology by using immunohistochemistry techniques confirmed a diagnosis of a diffuse large B-cell lymphoma. In conclusion, dentists and oral maxillofacial surgeons who encounter patients with a suspicious oral lesion inconsistent with the presenting head/neck/face complaint, must include malignancy as part of their differential diagnosis.

\section{Keywords}

Mandible, Diffuse Large B Cell Lymphoma, Non-Hodgkin's Lymphoma, Periapical Lesion, Oral Cancer

Subject Areas: Dentistry, Hematology, Oncology, Surgery \& Surgical Specialties

\footnotetext{
${ }^{*}$ Corresponding author.
}

How to cite this paper: Tetik, A., Peskersoy, C., Koyuncu, B.Ö., Solmaz, M.C. and Saydam, G. (2016) Primary Extranodal Non-Hodgkin's Lymphoma Mimicking a Painful Gingival Swelling: A Case Report. Open Access Library Journal, 3: e2363. http://dx.doi.org/10.4236/oalib.1102363 


\section{Introduction}

The type of non-Hodgkin lymphoma (NHL) most frequently diagnosed is diffuse large B-cell lymphoma (DLBCL) which is in turn the most frequent type ofprimary lymphoma of the oral cavity [1] [2]. It is the fifth most frequent cancer, accounting for $30 \%-40 \%$ of all cases reported [3]. DLBCL is an aggressive lymphoma and like most NHLs, there is a male predominance. Gastrointestinal tract, bone marrow, skin, breasts, central nervous system and testicles are the most frequently involved extranodal sites but primary lymphomas of the oral cavity uncommon [4]. DLBCL is a symptomatic and typically present as a rapidly enlarging mass, most usually lymph node enlargementin the neck or abdomen [5] [6]. Frequently, the initial symptoms of a large B-cell lymphoma of the oral cavity are a painless swelling, a nonhealing ulcer, fever, sweats and weight loss. A painless lymph node enlargement or a submucosal lesion in the junction between hard and soft palate are highly suspicious. Oral lymphoma often is a component of a disseminated disease process that may involve regional nodes as well. Other times, it may represent a primary extranodal disease confined to oral cavity or jaws, which is very rare [7].

The incidence rate of DLBCL in the European Union is $3-4 / 100,000 /$ year. The incidence increases with age from 0.3/100,000/year (35 - 39 years) to 26.6/100,000/year (80 - 84 years) [8].

The causes of DLBCL are not clear. Usually DLBCL arises from normal B cells, but it can also represent a malignant transformation of other types of lymphoma or leukaemia. An underlying immunodeficiency, is a significant risk factor. Infection with Epstein-Barr virus has also been found to contribute to the development of some subgroups of DLBCL [3].

The purpose of this report is to demonstrate a case of extra-nodal DLBCL arising in the mandible and to emphasize the difficulty of the diagnosis of the oral disease not improved with routine dental treatment.

\section{Case Report}

A 43-year-old male patient admitted to the Ege University, Department of Oral and Maxillofacial Surgery at the Faculty of Dentistry with one month complaint of gingival pain and swelling in the left side of mandibular premolar area at January 2014. Initially, symptoms were thought to be an odontogenic infection (apical perio-dontitis) related to the lower left lateral, canine, and premolar tooth and managed by antibiotics and anti-inflammatory medication. Misdiagnosed and unnecessary medication was ineffective and showed no improvement. Thus, patient was referred to the oral andmaxillofacial surgery department for a more definitive diagnosis and treatment. His medical history was unremarkable. He denied any constitutional symptoms, such as weight loss, fevers, chills, nausea, vomiting, malaise or fatigue. No medications were taken on a regular basis except this situation, there were no known allergies but the patient was a smoker for 22 years. Serological tests for hepatitis $\mathrm{B}$, and $\mathrm{C}$ virus as well as human immunodeficiency virus were negative. According to the patient, the lesion was present for approximately 18 to 24 months and it had a slow growing in the last six months. Intraoral soft tissue examination revealed a solid, hard mass on the buccal surface of the region of teeth number 31 - 34 (Figure 1) and mucosa of normal color. The intra-oral vestibular and lingual swelling extended from the mylohyoid muscle to lingula while the swelling measured around $3 \times 5 \mathrm{~cm}$ in size extraorallyand extending from the left corner of mental region to the inferior border of mandible. The skin over the swelling was stretched, and the surrounding tissues appeared to be normal. No scars, sinuses, ulcerations, or discoloration were detected over the swelling. On palpation, there was no local rise in temperature. Regional lymphadenopathy was existing and presenting as an inflammatory response due to odontogenic infections. Nevertheless vitality tests of the all teeth in that region were positive and even though there was no loosening or displacement of the teeth. Panoramic and periapical radiographs showed diffuse bone radiolucency (Figure 2 and Figure 3). There was mental nerve parasthesia on the left side of mandible. According to the clinical and radiographic examination and patient's history, provisional diagnosis was either one of oral benign carcinomas such as; ameloblastoma, Pindborg's tumor, central/peripheral giant cell granuloma. Therefore a biopsy had been needed and performed for histopathological examination. Conventional microscopy by using hematoxylin-eosin showed a lymphoproliferative lesion of uncertain nature with leomorphic round lymphocytelike cells, hyperchromatic nuclei, and atypical mitoses (Figure 4). On the basis of these findings, an immunohistochemical panel (antibodies CD3, CD10, CD20, Bcl-6, Bcl2, MUM1 and Ki-67) was performed to investigate the nature of these cells and the type of lympho-proliferative disorder in the left mandibular area (Figure 5). We found both biopsy specimens to be positive for CD 10, CD20, Bcl-6 and Ki 67 (60\%) and negative for CD3, CD30, Bcl-2, MUM-1. Histopathology by using 




Figure 1. Photograph showing initial presentation of the lesion in the left anterior area of the mandible.

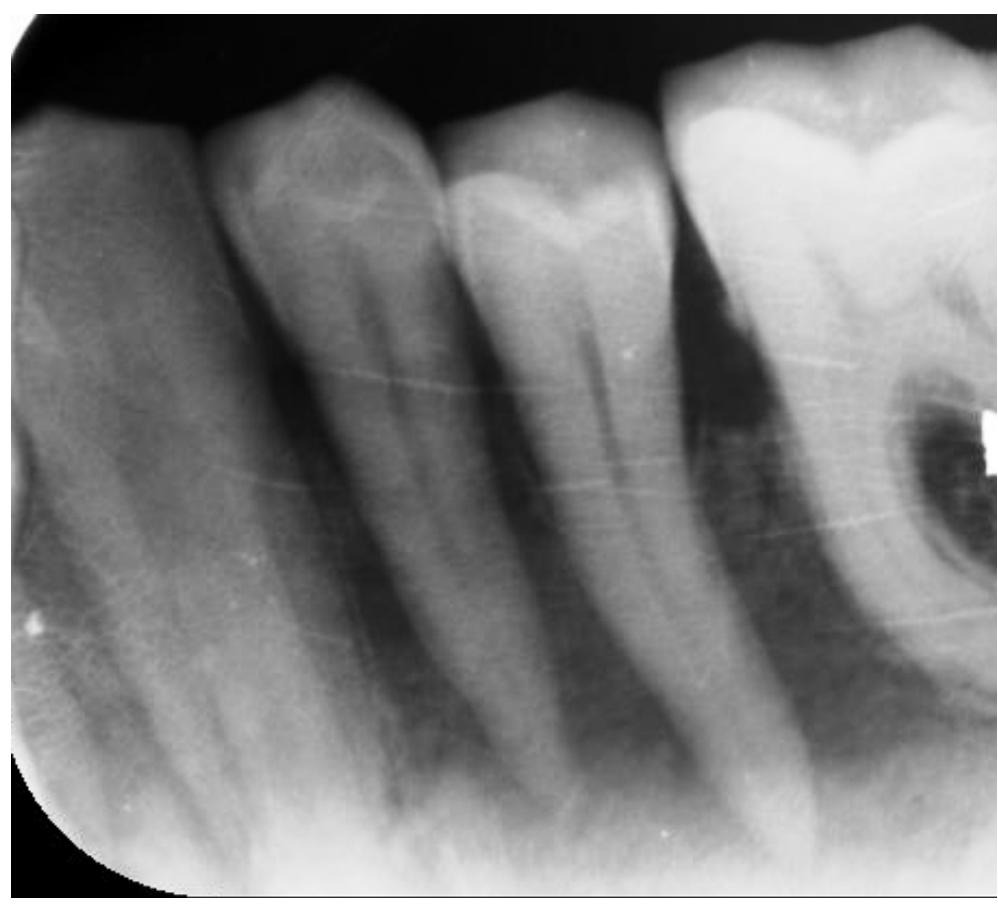

Figure 2. Periapical radiographs demonstrating irregular radiolucencies with indistinct margins seen in a 43-year-old male with swelling in area of left mandible canine to molars. 


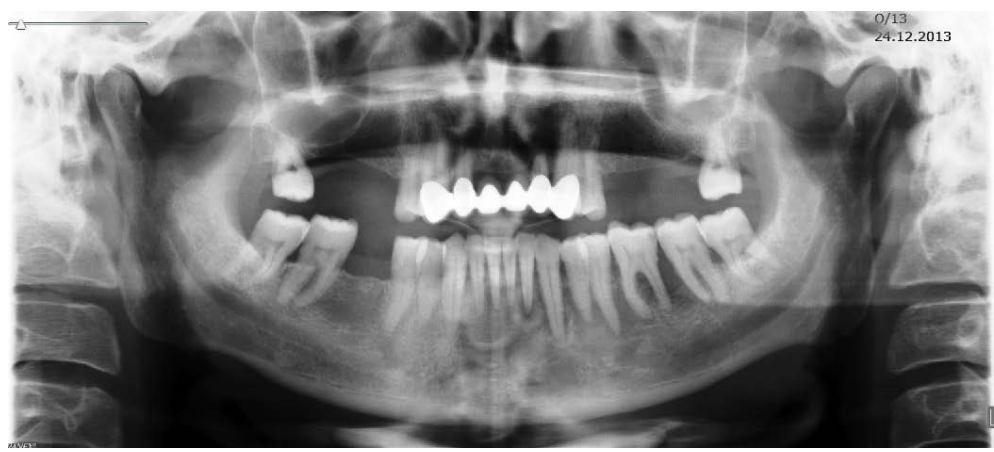

Figure 3. Panoramic radiograph demonstrating lesion arising within the mandible in the left body of the mandible.

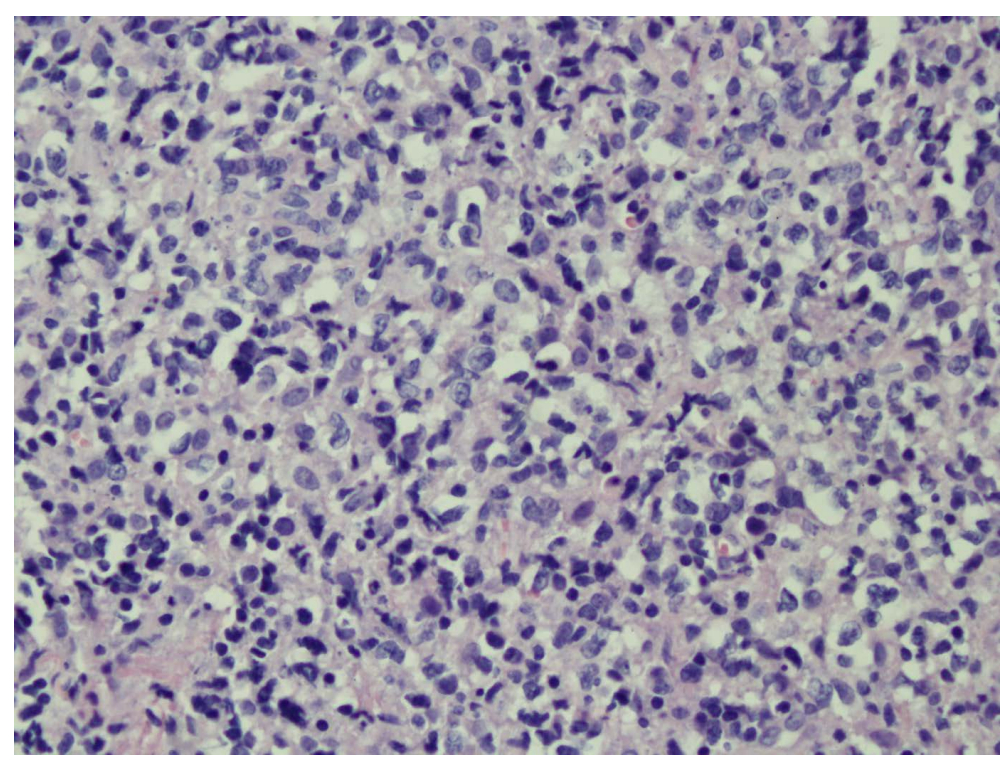

Figure 4. Diffuse large neoplastic lymphoid cell infiltration (H \& E staining, original magnification $40 \times$ ).
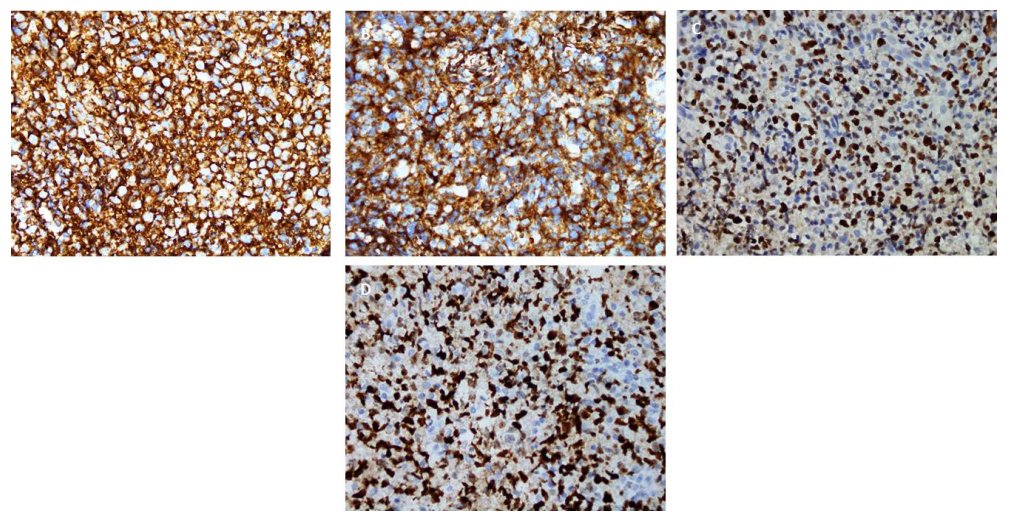

Figure 5. Immunohistochemical staining of neoplastic cells with A. CD20, B. CD10, C. BCL6, and D. a high proliferation index with Ki67 (original magnification, $40 \times)$.

immunohistochemistry techniques confirmed a diagnosis of a diffuse large B-cell lymphoma. The patient was referred to the Clinical Hematology Department for clinical staging by using complementary blood and bio- 
chemical tests, CT of the abdomen and chest, full b2-microglobulin tests, bone marrow biopsy, and myelogram. Six courses of combination chemotherapy with, CHOP (cyclophosphamide, hydroxydoxorubicin, oncovin, prednisone) and radiotherapy were scheduled. The sixth cycle of chemotherapy was stopped because of raised transaminase levels. There was complete remission.

\section{Discussion}

NHL is the second most common neoplasm of the head and neck region after SCC and the third most common group of malignant lesions of the oral region after SCC and salivary gland neoplasm [9] [10]. DLBCL is the most common type of NHL in the US and the western world accounting for $30 \%-40 \%$ of all cases [11]. DLBCL is an aggressive, rapidly growing neoplasm which is the most common lymphoid neoplasm affecting adults [12]. Up to $40 \%$ of all NHLs occur in extranodal sites, with the most common site being the gastrointestinal tract. The second most common site for extranodal NHLs is head and neck area where the majority of cases arise in Waldeyer's ring [13]. Moreover, 2\% - 3\% of these extra nodal cases may occur primarily in the oral cavity and jaws [14]. Jaw involvement of NHL is rare, but among jaw lesions, the maxilla is more frequently involved than the mandible [15]-[17]. NHL in the mandible accounts for only $0.6 \%$ of all NHL [18]-[20]. Because of its low frequency, primary lymphoma of the mandible is often misdiagnosed clinically [5] [18] [20]. In our case, the mandible was involved. The most frequent site of the occurrence in the mandible is the body [21], which is consistent with our case.

NHL generally affects the elderly, especially over the 6th decade of life, and the male: female ratio was 6:3 [22]. There are no characteristic clinical features of NHL of the oral region. The most common presenting symptoms are the presence of numbness, tooth mobility, swelling, unexplained dental pain, or ill-defined lytic osseous changes local swelling, pain or discomfort and ulcer [23]. Our case involved a 43-year-old male whose sex, and oral findings were compatible with the literature.

Bone swelling is the most frequent clinical presentation in jaw lymphoma, often associated with teeth mobility, pain and neurological disturbance [24]. Our case showed painful swelling in association with teeth mobility and mental nerve paresthesia.

Radiographic signs of bone involvement may be absent in $10 \%-20 \%$ of cases and if seen may not be specific. Lack of specific imaging characteristics can cause difficulty and delay in diagnosis. Diffuse bone destruction may cause appearing of a solitary defect or lowering of alveolar bone margin resembling periodontitis [14]. Radiographic findings in our case included a solitary osteolytic lesion with ill-defined margins in the anterior and premolar region of mandible.

The diagnosis was established through histological examination of biopsy tissue, coupled with immunohistochemical phenotyping. Immunohistochemistry plays an important role in distinguishing cell types and differential diagnosis [25]. We used CD3(marker for T-cells and NK cells), CD10 (marker for follicular center B-cells and granulocytes), CD20(selective marker that recognizes a subpopulation of B-cells), CD30 (marker for activated T- and B-cells), Bcl-6(B-cell lymphoma 6), Bcl-2 (B-cell lymphoma 2), MUM1 (Multiple myeloma oncogene 1) and Ki-67 (proliferation marker) and found both biopsy specimens to be positive for CD 10, CD20, Bcl-6 and Ki 67 (60\%) and negative for CD3, CD30, Bcl-2, MUM-1. We consequently diagnosed DLBCL.

The radiographic images of different periapical lesions may be similar [13] [26] [27], which poses a challenge for diagnosis. Lesions that mimic apical periodontitis, such as this case, must be included in the differential diagnosis. Other differential diagnosis includes a dental abscess, periodontal infection or benign reactive hyperplasia. Our patient also was initially treated for suspected periodontal and endodontic disease but as the swelling was progressive, he underwent an incisional biopsy that rendered a diagnosis of diffuse large B-cell lymphoma.

Regarding therapy, localized low-grade lymphomas are treated with radiotherapy, while aggressive chemotherapy is used for diffuse high-grade ones. A combination of chemotherapy and radiotherapy is used to treat patients with localized high-grade lymphomas. The surgical approach is limited to obtaining a specimen sufficient for a complete histological examination [24]. As DLBCL is an aggressive, rapidly growing neoplasm and this case was localized, it seems that a combination of chemotherapy and radiotherapy would be the most appropriate choice.The prognosis is excellent in localized disease, whereas in disseminated disease, it is less favorable [14]. 


\section{Conclusion}

Symptoms such as swelling, tooth mobility, nerve parasthesia and pain may lead to an incorrect diagnosis, because these symptoms are often present in common dental diseases.These findings in a delay in diagnosing NHL which reduces the survival rate. Therefore, dentists and oral maxillofacial surgeons who encounter patients with a suspicious oral lesion inconsistent with the presenting head/neck/face complaint, must include malignancy as part of their differential diagnosis. It is important for the clinicians to be aware of the various clinical manifestations of NHL of the oral cavity and of the maxillofacial region to diagnose this malignant condition quickly and appropriately.

\section{Conflicts of Interest}

There are no conflicts of interest.

\section{Consent}

Written informed consent was obtained from the patient for publication of this case report and any accompanying images.

\section{References}

[1] Solomides, C.C., Miller, A.S., Christman, R.A., Talwar, J. and Simpkins, H. (2002) Lymphomas of the Oral Cavity: Histology, İmmunologic Type, and İncidence of Epstein-Barr Virus İnfection. Human Pathology, 33, 153-157. http://dx.doi.org/10.1053/hupa.2002.30721

[2] Velasquez, W.S., Fuller, L.M., Jagannath, S., Tucker, S.L., North, L.B., Hagemeister, F.B., et al. (1991) Stages I and II Diffuse Large Cell Lymphomas: Prognostic Factors and Long-Term Results with CHOP-Bleo and Radiotherapy. Blood, 77, 942-947.

[3] Swerdlow, S.H., Campo, E., Harris, N.L., Jaffe, E.S., Pileri, S.A., Stein, H., et al. (2008) WHO Classification of Tumours of Haematopoietic and Lymphoid Tissues. 4th Edition, IARC Press, Lyon.

[4] Spatafore, C.M., Keyes, G. and Skidmore, A.E. (1989) Lymphoma: An Unusual Oral Presentation. Journal of Endontics, 15, 438-441. http://dx.doi.org/10.1016/S0099-2399(89)80179-7

[5] Kolokotronis, A., Konstantinou, N., Christakis, I., Papadimitriou, P., Matiakis, A., Zaraboukas, T., et al. (2005) Localized B-Cell Non-Hodgkin's Lymphoma of Oral Cavity and Maxillofacial Region: A Clinical Study. Oral Surgery, Oral Medicine, Oral Pathology, Oral Radiology, and Endodontology, 99, 303-310. http://dx.doi.org/10.1016/j.tripleo.2004.03.028

[6] Wolvius, E.B., van der Valk, P., van der Wal, J.E., van Diest, P.J., Huijgens, P.C., van der Waal, I., et al. (1994) Primary Extranodal Non-Hodgkin Lymphoma of the Oral Cavity. An Analysis of 34 Cases. European Journal of Cancer Part B Oral Oncology, 30B, 121-125. http://dx.doi.org/10.1016/0964-1955(94)90063-9

[7] Lin, A.Y. and Tucker, M.A. (1998) Epidemiology of Hodgkin’s Disease and Non-Hodgkin’s Lymphoma. In: Canellos, G.P., Lister, T.A., Sklar, J.L., Eds., The Lymphomas, Saunders, Philadelphia, 43-60.

[8] Morgan, G., Vornanen, M., Puitinen, J., et al. (1997) Changing Trends in the İncidence of Non-Hodgkin’s Lymphoma in Europe. Biomed Study Group. Annals of Oncology, 8, 49-54. http://dx.doi.org/10.1093/annonc/8.suppl_2.S49

[9] Villa, A., Mariani, U. and Villa, F. (2010) T-Cell Lymphoma of the Oral Cavity: A Case Report. Australian Dental Journal, 55, 203-206. http://dx.doi.org/10.1111/j.1834-7819.2010.01212.x

[10] Vaswani, B., Shah, M., Shah, P.M., Parikh, B.J., Anand, A.S. and Sharma, G. (2008) Non Hodgkin’s Lymphoma of Tongue-A Case Report. Indian Journal of Medical and Paediatric Oncology, 29, 59-61. http://dx.doi.org/10.4103/0971-5851.51448

[11] Bhattacharyya, I., Chehal, H.K., Cohen, D.M. and Al-Quran, S.Z. (2010) Primary Diffuse Large B-Cell Lymphoma of the Oral Cavity: Germinal Center Classification. Head and Neck Pathology, 4, 181-191. http://dx.doi.org/10.1007/s12105-010-0184-4

[12] Bulut, E., Bekcioglu, B., Gunhan, O. and Sener, I. (2011) Diffuse Large B-Cell Lymphoma with Oral Manifestations. Journal of Craniofacial Surgery, 22, 1144-1147. http://dx.doi.org/10.1097/SCS.0b013e318210b940

[13] Regezi, J.A., Sciubba, J.J. and Jordan, R.C.R. (2008) Oral Pathology: Clinical Pathologic Correlations. Elsevier, China, 223.

[14] Kini, R., Saha, A. and Naik, V. (2009) Diffuse Large B-Cell Lymphoma of Mandible: A Case Report. Medicina Oral Patologia Oral y Cirugia Bucal, 14, 421-424. 
[15] Parrington, S.J. and Punnia-Moorthy, A. (1999) Primary Non-Hodgkin's Lymphoma of the Mandible Presenting Following Tooth Extraction. British Dental Journal, 187, 468-470. http://dx.doi.org/10.1038/sj.bdj.4800308

[16] Gusenbauer, A.W., Katsikeris, N.F. and Brown, A. (1990) Primary Lymphoma of the Mandible: Report of a Case. Journal of Oral and Maxillofacial Surgery, 48, 409-415. http://dx.doi.org/10.1016/0278-2391(90)90442-5

[17] Kawasaki, G., Nakai, M., Mizuno, A., Nakamura, T. and Okabe, H. (1997) Malignant Lymphoma of the Mandible: Report of a Case. Oral Surgery, Oral Medicine, Oral Pathology, Oral Radiology, and Endodontology, 83, $345-349$. http://dx.doi.org/10.1016/S1079-2104(97)90241-9

[18] Adouani, A., Bouguila, J., Jeblaoui, Y., Ben Aicha, M., Abdelali, M.A., Hellali, M., Zitouni, K., Amani, L. and Issam, Z. (2008) B-Cell Lymphoma of the Mandible: A Case Report. Clinical Medicine: Oncology, 2, 445-450.

[19] Mnejja, M., Hammami, B., Kolsi, N., et al. (2010) B-Cell Lymphoma of the Mandible. European Annals of Otorhinolaryngology, Head and Neck Diseases, 127, 186-188. http://dx.doi.org/10.1016/j.anorl.2010.07.009

[20] Longo, F., De Maria, G., Esposito, P. and Califano, L. (2004) Primary Non-Hodgkin’s Lymphoma of the Mandible. Report of a Case. International Journal of Oral and Maxillofacial Surgery, 33, 801-803. http://dx.doi.org/10.1016/j.ijom.2003.12.003

[21] Kirita, T., Ohgi, K., Shimooka, H., Okamoto, M., Yamanaka, Y. and Sugimura, M. (2000) Primary Non-Hodgkin’s Lymphoma of the Mandible Treated with Radiotherapy, Chemotherapy, and Autologous Peripheral Blood Stem Cell Transplantation. Oral Surgery, Oral Medicine, Oral Pathology, Oral Radiology, and Endodontology, 90, 450-455. http://dx.doi.org/10.1067/moe.2000.108441

[22] Maheshwari, G., Baboo, H.A., Shah, N.M., Patel, M.H. and Shah, R. (2001) Primary Non-Hodgkin's Lymphoma of the Oral Tongue. Turkish Journal of Cancer, 31, 121-124.

[23] Angiero, F., Stefani, M. and Crippa, R. (2006) Primary Non-Hodgkin's Lymphoma of the Mandibular Gingiva with Maxillary Gingival Recurrence. Oral Oncology Extra, 42, 123-128. http://dx.doi.org/10.1016/j.o0e.2005.10.008

[24] Longo, F., De Maria, G., Esposito, P. and Califano, L. (2004) Primary Non-Hodgkin’s Lymphoma of the Mandible. Report of a Case. International Journal of Oral and Maxillofacial Surgery, 33, 801-803. http://dx.doi.org/10.1016/j.ijom.2003.12.003

[25] Biggar, R.J. and Rabkin, C.S. (1992) The Epidemiology of Acquired İmmunodeficiency Virus Related Lymphomas. Current Opinion in Oncology, 4, 883-893. http://dx.doi.org/10.1097/00001622-199210000-00011

[26] Bueno, M.R., Carvalhosa, A.A.C., Castro, P.H.S., et al. (2008) Mesenchymal Chondrosarcoma Mimicking Apical Periodontitis. Journal of Endodontics, 34, 1415-1419. http://dx.doi.org/10.1016/j.joen.2008.08.016

[27] Faitaroni, L.A., Bueno, M.R., Carvalhosa, A.A., et al. (2008) Ameloblastoma Suggesting Large Apical Periodontitis. Journal of Endodontics, 34, 216-219. http://dx.doi.org/10.1016/j.joen.2007.11.010

\section{Abbreviations}

Bcl-2: B-cell lymphoma 2

Bcl-6: B-cell lymphoma 6

CD3: Marker for T-cells and NK cells

CD10: Marker for follicular center B-cells and granulocytes

CD20: Selective marker that recognizes a subpopulation of B-cells

CD30: Marker for activated T- and B-cells

DLBCL: Diffuse large B-cell lymphoma

Ki-67: Proliferation marker

NHL:Non-Hodgkin lymphoma

MUM1: Multiple myeloma oncogene 1 